\title{
Fast-Response Liquid Crystals for 6G Optical Communications
}

\author{
Junyu Zou ${ }^{1}$, Zhiyong Yang ${ }^{1}{ }^{(\mathbb{D}}$, Chongchang Mao ${ }^{2}$ and Shin-Tson $\mathrm{Wu}^{1, *}$ (1) \\ 1 College of Optics and Photonics, University of Central Florida, Orlando, FL 32816, USA; \\ zoujunyuwinnie@Knights.ucf.edu (J.Z.); zhiyyang@knights.ucf.edu (Z.Y.) \\ 2 ElectroSience Lab, Ohio State University, 1330 Kinnear Road, Columbus, OH 43212, USA; mao.550@osu.edu \\ * Correspondence: swu@creol.ucf.edu; Tel.: +1-407-823-4763
}

check for updates

Citation: Zou, J.; Yang, Z.; Mao, C.; Wu, S.-T. Fast-Response Liquid Crystals for 6G Optical Communications. Crystals 2021, 11, 797. https://doi.org/10.3390/ cryst11070797

Academic Editors: Kohki Takatoh, Jun Xu and Akihiko Mochizuki

Received: 15 June 2021

Accepted: 6 July 2021

Published: 8 July 2021

Publisher's Note: MDPI stays neutral with regard to jurisdictional claims in published maps and institutional affiliations.

Copyright: (c) 2021 by the authors. Licensee MDPI, Basel, Switzerland. This article is an open access article distributed under the terms and conditions of the Creative Commons Attribution (CC BY) license (https:// creativecommons.org/licenses/by/ $4.0 /)$.

\begin{abstract}
We report two high birefringence and low viscosity nematic mixtures for phase-only liquidcrystal-on-silicon spatial light modulators. The measured response time (on + off) of a test cell with $2 \pi$ phase change at $1550 \mathrm{~nm}, 5 \mathrm{~V}$ operation voltage, and $40^{\circ} \mathrm{C}$ is faster than $10 \mathrm{~ms}$. To improve the photostability, a distributed Bragg reflector is designed to cutoff the harmful ultraviolet and blue wavelengths. These materials are promising candidates for future $6 \mathrm{G}$ optical communications.
\end{abstract}

Keywords: liquid crystals; spatial light modulator; liquid-crystal-on-silicon; photostability

\section{Introduction}

Dense wavelength division multiplexing (DWDM) optical networks [1] are the foundation of global internet communications. With an ability to transport over 100 informationbearing wavelengths on a single optical fiber [2], DWDM nullifies the cost-per-bit of communicating services. The technology makes it economically viable for businesses to move their computing and storage to the Cloud and for consumers to stream video ubiquitously. It is also an essential enabler for the 5th generation (5G) [3] and 6th generation $[4,5](6 \mathrm{G})$ networks and most other advanced telecommunications. Ensuring high capacity, ultra-high reliability, and low latency over multiple simultaneous connections in the same communication network infrastructure not only requires development of 5G/6G mobile fronthaul networks but also requires major developments at the wired network backhaul side.

In order to increase the data transport rate and reduce the signal latency, reconfigurable add/drop multiplexer (ROADM) systems [6,7] are widely deployed in DWDM network nodes, as illustrated in Figure 1a. ROADM systems can facilitate the addition of new services without requiring an expensive upgrade or substantial change to telecom networks [8]. A ROADM allows remote, precise, and flexible selection of wavelengths, so it significantly increases the network capacity without major expense. The ROADM market is forecasted to have tremendous growth following the progress of deployment of $5 \mathrm{G} / 6 \mathrm{G}$ networks.

Referring to Figure $1 \mathrm{~b}$, the $1 \times N$ wavelength selective switch (WSS) and $M \times N$ Add/Drop WSS (AdWSS) are two core subsystems of a ROADM system [9]. The optical system of a WSS, as shown in Figure 2a, performs wavelength de-multiplexing, beam steering, and then wavelength multiplexing. A WSS system can direct an optical beam at any wavelength to any desired output port. Several technologies have been used for light beam steering, such as micro-electromechanical system (MEMS) arrays [10], liquid crystal cells and crystal wedges [11], and liquid-crystal-on-silicon (LCoS) phase modulators [12]. Among them, LCoS phase modulators are used in most current WSS systems because they are easier to develop high port count WSS systems and to realize dynamic control of the channel center with high resolution $[13,14]$. As Figure $2 b$ depicts, a blazed grating is formed on the LCoS phase modulator corresponding to each incident beam (e.g., red, green, and blue) when a designed profile of spatially dependent voltages is applied to the 
pixels. When a light beam is incident upon the grating, the reflected beam is diffracted to a designed direction. Changing the blazed grating pitch enables the grating to diffract an incident optical beam to different angles, resulting in $1 \times N$ optical switching.

(a)

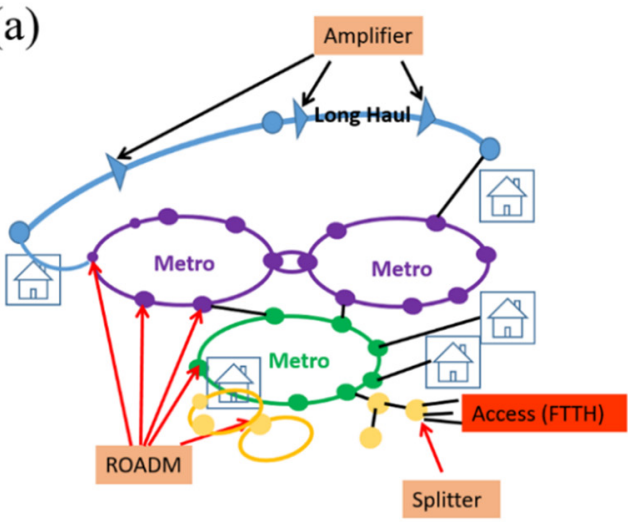

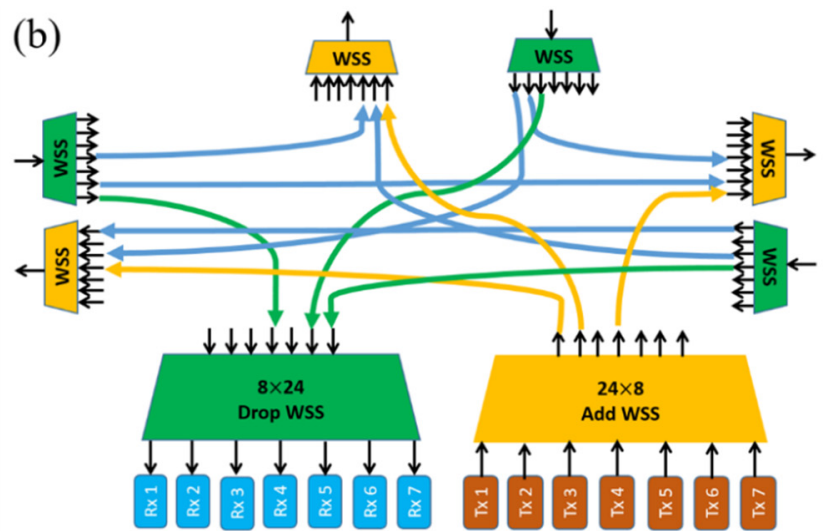

Figure 1. (a) Schematic diagram of optical telecommunication network; (b) Example of ROADM architecture.

(a)

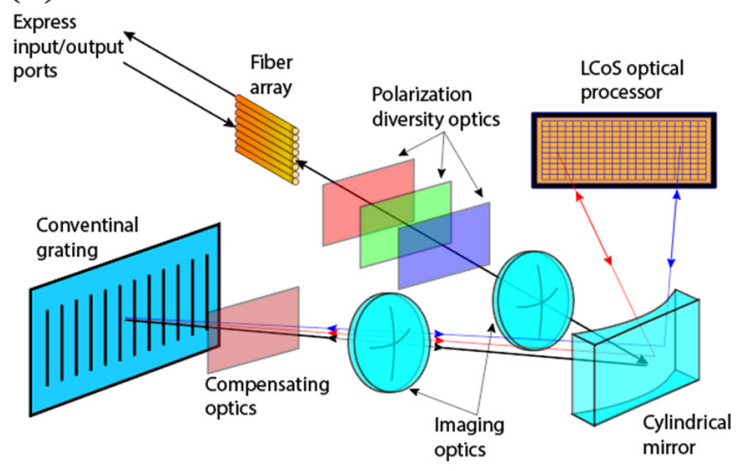

(b)

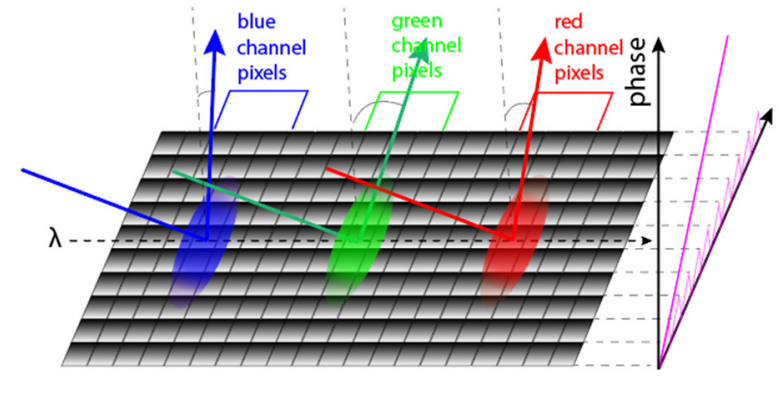

Figure 2. (a) The optical system of WSS; (b) illustration of beam steering principle using an LCoS phase modulator.

Currently, the optical network industry faces significant challenges to develop high port count, high switching speed, and low insertion loss WSS systems. Generally, current WSS systems have a beam steering time longer than $1 \mathrm{~s}$. Such a steering time consists of two parts: the frame data loading time onto LCoS silicon backplane and the liquid crystal (LC) response time [15]. The latter is usually much slower than the former. For example, the frame data refreshing time is $\sim 8 \mathrm{~ms}$ when an LCoS phase modulator is operated at a frame rate of $120 \mathrm{~Hz}$. The frame data loading time can be further reduced by increasing the frame rate if necessary. In current WSS systems, LC response time is much longer than data loading time, resulting in a slow beam steering speed. Therefore, to increase the beam steering speed, we need to develop fast-response LC materials.

In a WSS, to achieve the required hitless switching, beam steering is performed with several steps, for example, 4-6 steps. Therefore, increasing the LC switching speed can significantly reduce the system's beam steering time. For example, if the LC switching time is less than $10 \mathrm{~ms}$, then the system's beam steering time can be reduced by one order from current millisecond switching time. More details about how LC materials influence the performance of WSS can be found in Ref. [16].

Fast-response LC materials have been developed for display applications [17] and phase-only modulators for beam steering applications $[15,18,19]$. Most commercially available LC mixtures exhibit a birefringence $\Delta n<0.3$ at $\lambda=589.3 \mathrm{~nm}$ in order to keep a good photostability [16]. However, for optical telecommunications, the wavelength is typically at $\lambda=1550 \mathrm{~nm}$. As the wavelength increases, $\Delta n$ gradually decreases and then 
saturates [15]. Moreover, for an LCoS phase modulator, the required phase change is $2 \pi$, instead of $1 \pi$ for the corresponding intensity modulator. That means that, if we use the same LC material for intensity and phase modulators, the latter will have a $4 \times$ slower response time. Thus, it is really challenging to achieve a fast response time for the intended 5G/6G communications.

In this paper, we evaluate two fast-response LC materials, LCM-1107 and LCM-2018 (LC Matter). Both mixtures exhibit a high $\Delta n$ and relatively low viscosity. The measured response time is less than $10 \mathrm{~ms}$ at $5 \mathrm{~V}, \lambda=1550 \mathrm{~nm}$, and the intended operating temperature of an LCoS, which is between 40 and $60^{\circ} \mathrm{C}$. A distributed Bragg reflector is also designed to protect these high $\Delta n \mathrm{LC}$ materials from being damaged by the ambient UV (ultraviolet) and blue lights.

\section{Material Characterizations}

The physical properties of LCM-1107 and LCM-2018 are listed in Table 1. Differential scanning calorimetry (DSC, TA Instruments Q100) was applied to measure the melting temperature $\left(T_{m}\right)$ and clearing temperature $\left(T_{c}\right)$. From Table 1 , these two materials show a wide nematic range to meet the requirements for $\mathrm{LCoS}$ applications in $6 \mathrm{G}$ communications. The dielectric constants were measured with a multifrequency LCR meter, HP-4274. Both mixtures have a reasonably large dielectric constant $(\Delta \varepsilon>15)$, which helps to lower the threshold voltage. According to the measured free relaxation response time of the test cell [20], the viscoelastic constant $\gamma_{1} / K_{11}$ of each mixture can be extracted. For comparison, we also include the properties of a Merck high birefringence LC material, BL038 [21], as shown in Table 1. From Table 1, we can see that these two materials exhibit high $\Delta n$, large dielectric constants, and relatively low viscoelastic constants.

Table 1. Measured physical properties of LCM-1107, LCM-2018, and BL038 at $T=22{ }^{\circ} \mathrm{C}$.

\begin{tabular}{cccc}
\hline LC Mixture & LCM-1107 & LCM-2018 & BL038 \\
\hline$T_{C}\left({ }^{\circ} \mathrm{C}\right)$ & 99.2 & 115.6 & 100.0 \\
$T_{m}\left({ }^{\circ} \mathrm{C}\right)$ & $<-20$ & $<-20$ & - \\
$\Delta n @ 1550 \mathrm{~nm}$ & 0.312 & 0.344 & $0.257(@ 633 \mathrm{~nm})$ \\
$\Delta \varepsilon @ 1 \mathrm{kHz}$ & 16.3 & 17.3 & 14.4 \\
$\varepsilon_{\perp} @ 1 \mathrm{kHz}$ & 4.84 & 5.07 & 5.0 \\
$K_{11}(\mathrm{pN})$ & 12.7 & 14.6 & 19.1 \\
$\gamma_{1} / K_{11}\left(\mathrm{~ms} / \mu \mathrm{m}^{2}\right)$ & 17.6 & 14.5 & 30.2 \\
\hline
\end{tabular}

\subsection{Birefringence}

To measure $\Delta n$, LCM-1107 and LCM-2018 were filled into two homogeneous cells, whose cell gaps are $d=8.03 \mu \mathrm{m}$ and $d=8.10 \mu \mathrm{m}$, respectively. The pretilt angle of the rubbed polyimide alignment layers is about $3^{\circ}$. Then, the cell was mounted on a Linkam heating stage, and the temperature was controlled through a temperature programmer TMS94. The test cell was sandwiched between two crossed polarizers and the LC director was oriented at $45^{\circ}$ with respect to the optical axis of the polarizer. During the measurement, the sample was activated with a $1 \mathrm{kHz}$ square-wave AC voltage, and the input wavelength $(\lambda=1550$ $\mathrm{nm}$ ) was from a laser diode. The transmitted light was detected by an infrared (IR) detector, so that we could obtain the voltage-transmittance (V-T) curve. This V-T curve can be converted to a voltage-phase $(V-\Phi)$ curve [22].

Next, the birefringence at a temperature can be calculated from the measured phase retardation. Figure 3 shows the measured (dots and triangles) and fitting (solid line) results of these two materials at different temperatures. The temperature-dependent birefringence can be described by the following equation [23]:

$$
\Delta n=\Delta n_{0} S=\Delta n_{0}\left(1-T / T_{\mathcal{C}}\right)^{\beta} .
$$




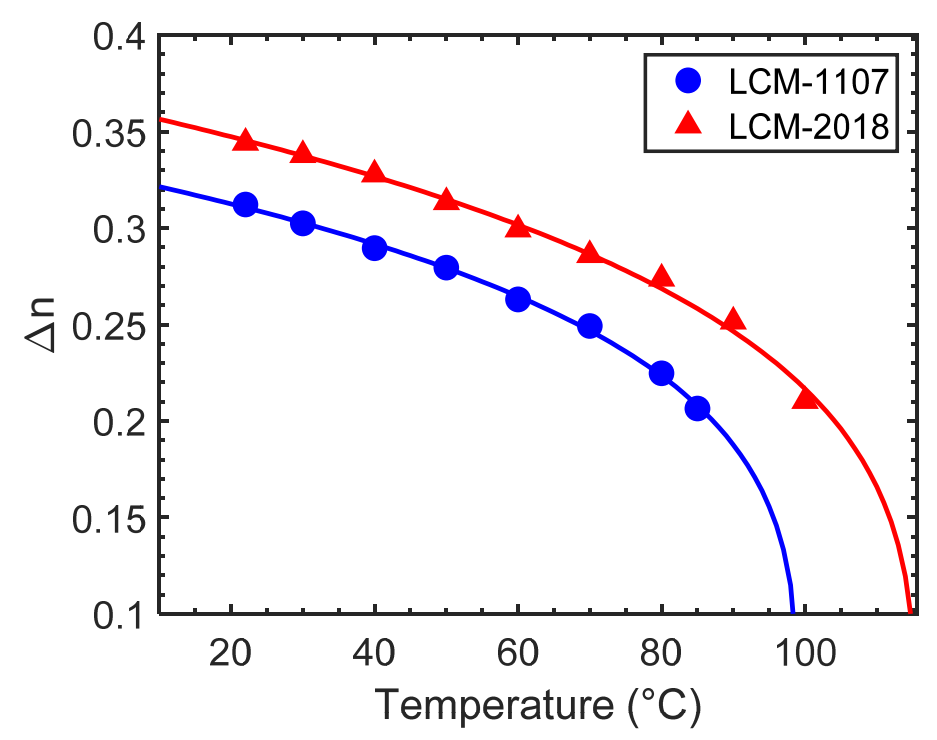

Figure 3. Temperature-dependent birefringence of LCM-1107 and LCM-2018 at $\lambda=1550 \mathrm{~nm}$ and $f=1 \mathrm{kHz}$. Dots and triangles are measured data and solid lines are fitting curves with Equation (1).

In Equation (1), $S$ is the order parameter, $T_{\mathcal{C}}$ (unit: $\mathrm{K}$ ) is the clearing temperature of the LC (measured by DSC), $\Delta n_{0}$ represents the extrapolated birefringence when $T=0 \mathrm{~K}$, and exponent $\beta$ is a material parameter. The values of both $\Delta n_{0}$ and $\beta$ can be obtained by fitting the experimental data with Equation (1), whose results are listed in Table 2.

Table 2. Fitting parameters obtained through Equations (1)-(3).

\begin{tabular}{|c|c|c|c|c|c|c|}
\hline $\begin{array}{c}\text { LC } \\
\text { Mixture }\end{array}$ & $\Delta n_{0}$ & $\beta$ & $\begin{array}{c}G @ 40{ }^{\circ} \mathrm{C} \\
\left(\mu \mathrm{m}^{-2}\right)\end{array}$ & $\begin{array}{c}\lambda^{* @ 40}{ }^{\circ} \mathrm{C} \\
(\mu \mathrm{m})\end{array}$ & $\begin{array}{c}A \\
\left(\mathrm{~ms} / \mu \mathrm{m}^{2}\right)\end{array}$ & $\begin{array}{c}E_{a} \\
(\mathrm{meV})\end{array}$ \\
\hline LCM-1107 & 0.451 & 0.236 & 3.67 & 0.276 & $\begin{array}{c}1.69 \times \\
10^{-5}\end{array}$ & 342 \\
\hline LCM-2018 & 0.500 & 0.260 & 3.91 & 0.284 & $1.16 \times 10^{-4}$ & 288 \\
\hline
\end{tabular}

For LiDAR (light detection and ranging) and 6G optical communications, the employed wavelength could be different. Therefore, we also measured the wavelengthdependent birefringence of these two materials. In the experiment, we measured the wavelength dispersion at the working temperature of LCoS, which is typically $40-60{ }^{\circ} \mathrm{C}$. Six different wavelengths were used: a He-Ne laser at $\lambda=632.8 \mathrm{~nm}$, a tunable Argon ion laser with $\lambda=457,488$, and $514 \mathrm{~nm}$, and two diode IR lasers at $\lambda=1060$ and $1550 \mathrm{~nm}$. The measured results (dots and triangles) are plotted in Figure 4. We can fit the experimental results with the following single-band birefringence dispersion equation [23]:

$$
\Delta n=G \frac{\lambda^{2} \lambda^{* 2}}{\lambda^{2}-\lambda^{* 2}}
$$




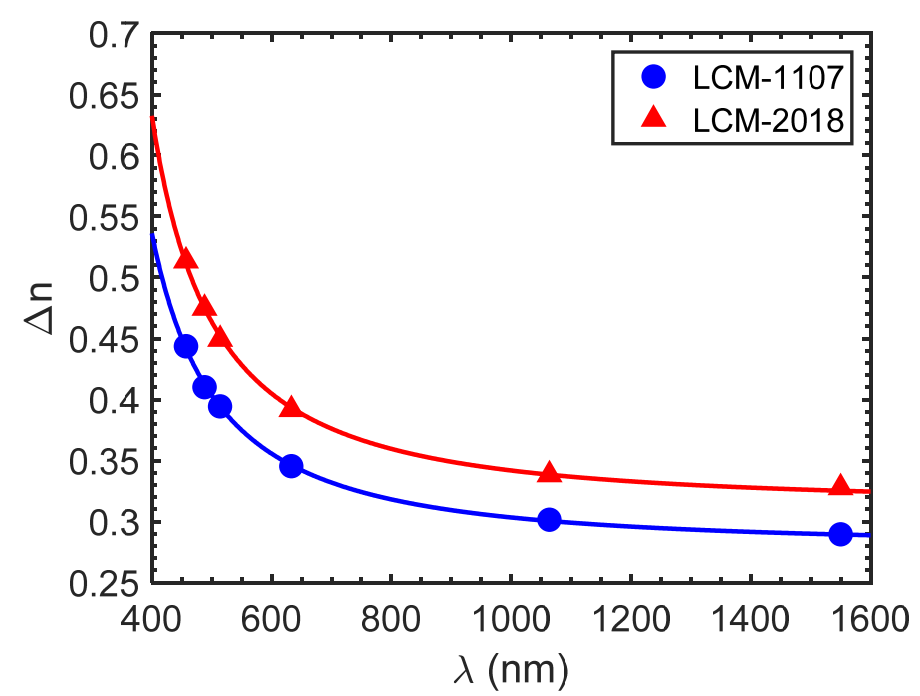

Figure 4. Wavelength-dependent birefringence of LCM-1107 and LCM-2018 at $40{ }^{\circ} \mathrm{C}$ and $1 \mathrm{kHz}$. Dots and triangles are measured data and solid lines are fitting curves with Equation (2).

Equation (2) has two fitting parameters: $G$ (proportionality constant) and $\lambda^{*}$ (mean resonance wavelength). The fitting results are listed in Table 2.

\subsection{Viscoelastic Constant}

The viscoelastic constant $\gamma_{1} / K_{11}$ is also an important parameter affecting the LCoS response time. We measured $\gamma_{1} / K_{11}$ through the transient decay time of an LC cell. The obtained results are plotted in Figure 5, where dots and triangles are the measured results, and solid lines are the fitting results using the following equation [24]:

$$
\frac{\gamma_{1}}{K_{11}}=A \frac{\exp \left(E_{a} / k_{B} T\right)}{\left(1-T / T_{c}\right)^{\beta}} .
$$

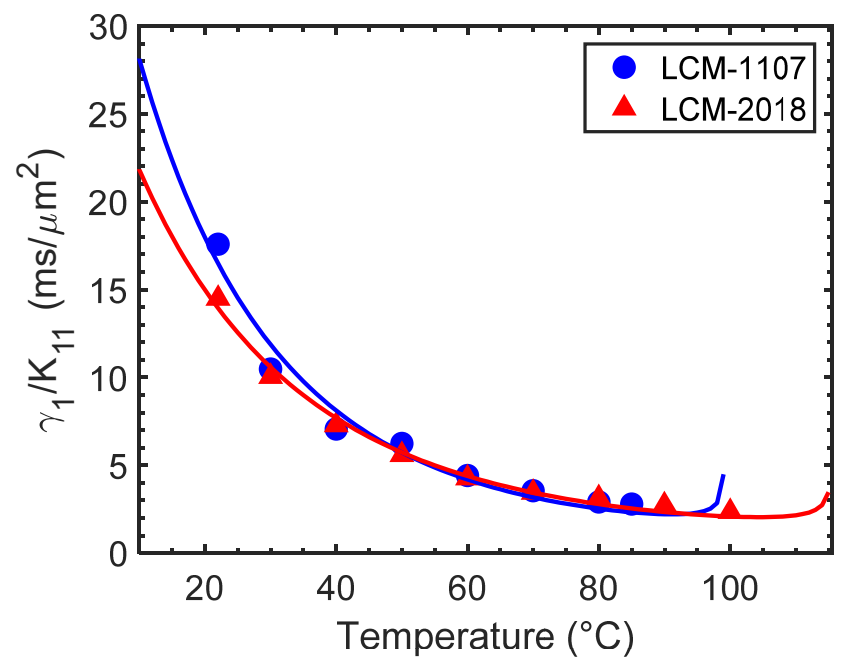

Figure 5. Temperature-dependent viscoelastic constant of LCM-1107 and LCM-2018. Dots and triangles are measured data and solid lines are fitting curves with Equation (3).

In Equation (3), $A$ is the proportionality constant, $E_{a}$ is the activation energy, and $k_{B}$ is the Boltzmann constant. Here, $A$ and $E_{a}$ are fitting parameters, whose values are also included in Table 2. 


\subsection{Figure of Merit}

Figure of merit, which is defined as FoM $=\Delta n^{2} /\left(\gamma_{1} / K_{11}\right)$, is a fair way to compare the electro-optic performance of different materials [24]. Based on the results in Figures 3 and 5, we can plot the temperature-dependent FoM as shown in Figure 6, where dots are experimental data and solid lines are the fitting curves using the definition of FoM, and Equation (2) for $\Delta n$ and Equation (3) for $\gamma_{1} / K_{11}$. From the figure, we can see that as the temperature increases, FoM increases first, reaching a peak, and then declines sharply as the temperature approaches $T_{\mathcal{c}}$. The reason the FOM shows such a tendency is that both $\Delta n$ and $\gamma_{1} / K_{11}$ decrease but at different rates as the temperature initially increases. In Figure $3, \Delta n$ decreases slowly as the temperature gradually increases, but the decreasing rate becomes more pronounced as the temperature approaches $T_{c}$. However, $\gamma_{1} / K_{11}$ shows an opposite trend, i.e., it decreases rapidly in the beginning and then gradually saturates as the temperature gets closer to $T_{\mathcal{c}}$. Detailed mechanisms have been explained in Ref. [24].
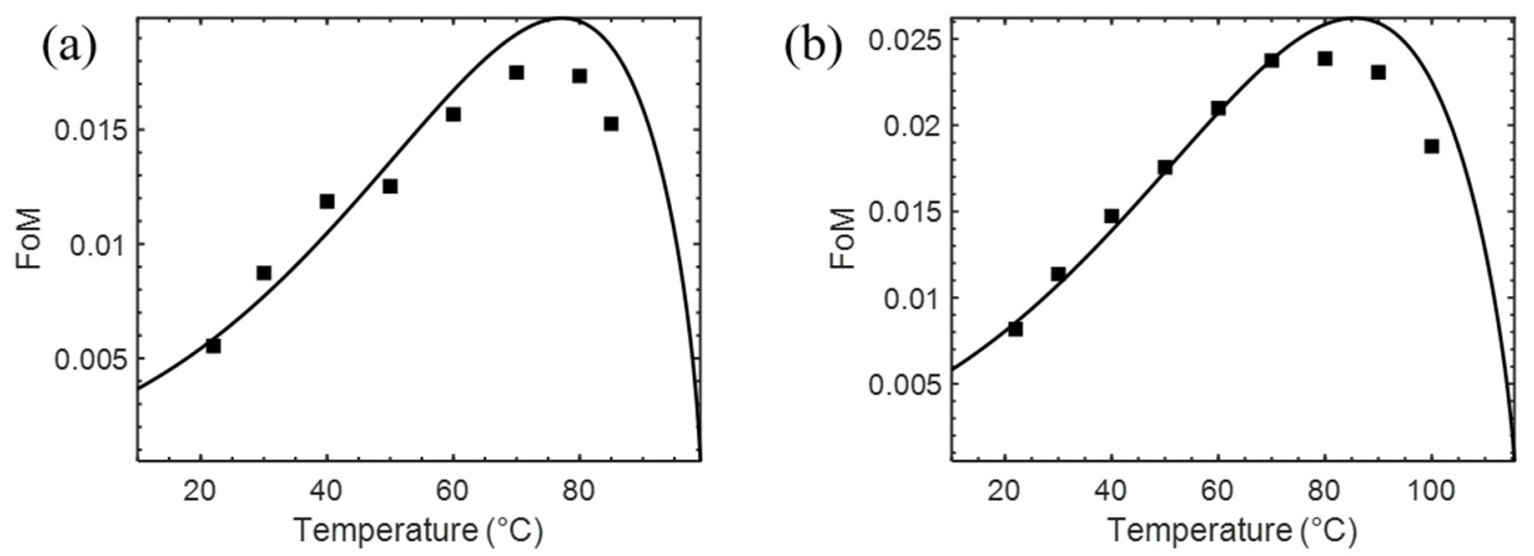

Figure 6. Temperature-dependent FoM of (a) LCM-1107 and (b) LCM-2018. Squares are measured data and solid lines are fitting curves.

\subsection{Voltage-Dependent Phase Change}

For a phase-only LCoS, we can select an optimal cell gap for each LC material to achieve $2 \pi$ phase change at the maximally allowable operation voltage, which is $5 \mathrm{~V}$ $\left(V_{2 \pi}=5 \mathrm{~V}\right)$, and the intended operation temperature and wavelength. In the experiment, for convenience we measured the voltage-dependent transmittance $(V-T)$ curves of these two materials using transmission-type LC cells at $\lambda=1550 \mathrm{~nm}$ and then converted to the voltage-dependent phase $(V-\Phi)$ curves depicted by red lines in Figure 7 . Since the operating temperature of a working LCoS device could vary from 40 to $60^{\circ} \mathrm{C}$ due to the thermal effects from the backplane driving circuits and the employed light source, we measured the electro-optic effects at 40,50 , and $60{ }^{\circ} \mathrm{C}$ for LCM-1107 (Figure 7a-c) and LCM-2018 (Figure 7d-f), respectively. From the measured results (red lines) shown in Figure 7 , when the applied voltage is $5 \mathrm{~V}$, the phase change is more than $2 \pi$, which means we can use a thinner cell gap (optimal cell gap) to achieve the desired $V_{2 \pi}=5 \mathrm{~V}$ at each temperature. Due to the limited available cell gaps in our lab, we extrapolated the $V-\Phi$ curve to the corresponding optimal cell gap as shown by the blue lines in Figure 7 . The optimal cell gaps and the extrapolated $V-\Phi$ curves are obtained according to the phase retardation equation $\delta=2 \pi d \Delta n / \lambda$. Since the cell gap is thinner, the response time is faster, as will be discussed quantitatively later. 

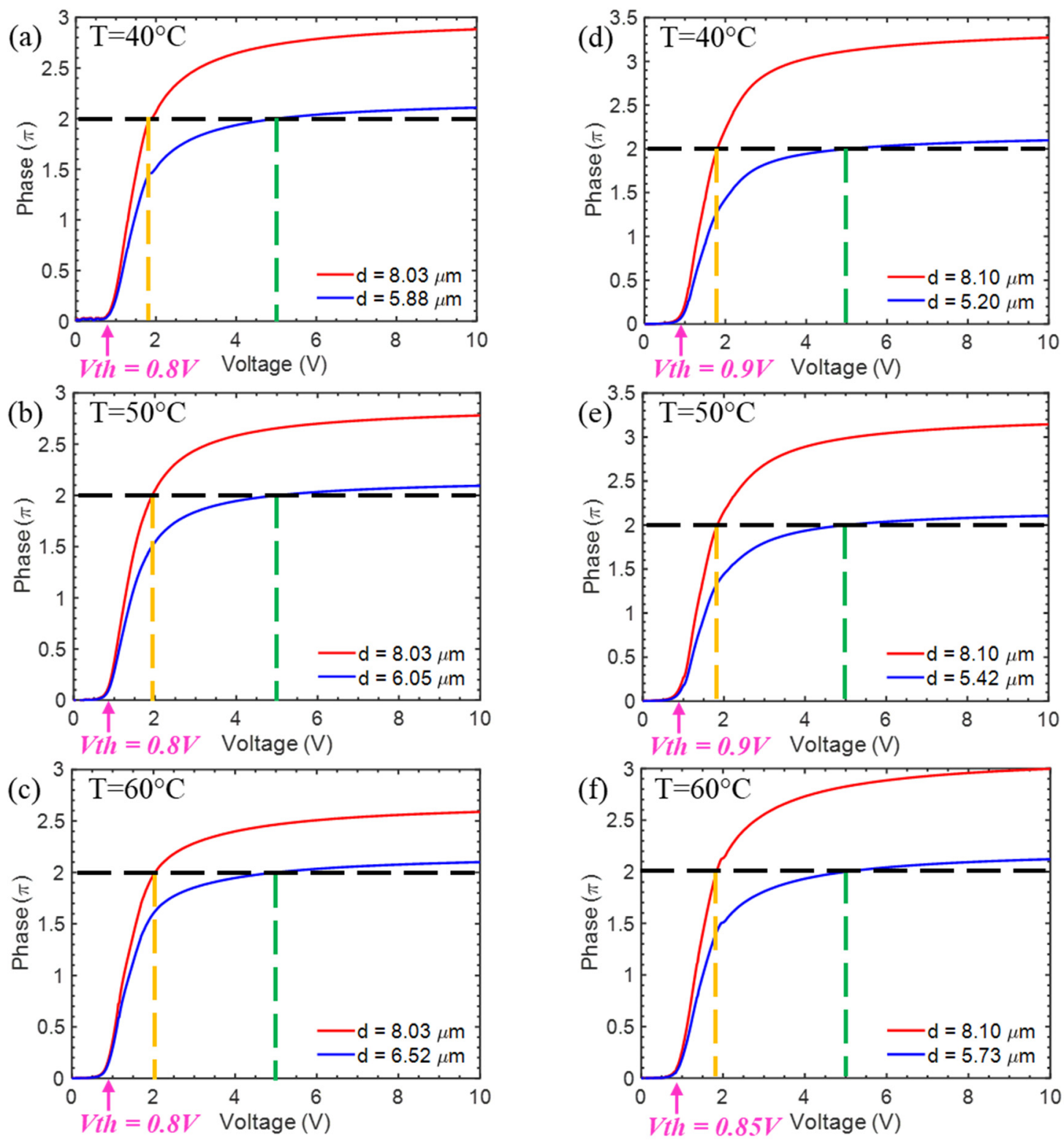

Figure 7. Measured (red lines) voltage-dependent phase change in a transmissive LCM-1107 cell (a-c) and LCM-2018 cell (d-f) at $\lambda=1550 \mathrm{~nm}$, and the extrapolated (blue lines) voltage-dependent phase change of the corresponding optimal cell gaps at $V_{2 \pi}=5 \mathrm{~V}_{\mathrm{rms}}$.

\subsection{Response Time}

The response time (rise time and decay time) of an LC phase modulator between two gray levels $\left(V_{1}\right.$ and $\left.V_{2}\right)$ depends on the viscoelastic constant, LC cell gap, threshold voltage, and operating voltages, which are described in the following equations [25]:

$$
\begin{gathered}
\tau_{o n}=\frac{\tau_{0}}{\left(V_{2} / V_{t h}\right)^{2}-1}, \\
\tau_{o f f}=\frac{\tau_{0}}{\left|\left(V_{1} / V_{t h}\right)^{2}-1\right|}, \\
\tau_{0}=\frac{\gamma_{1} d^{2}}{K_{11} \pi^{2}} .
\end{gathered}
$$


In Equations (4)-(6), $\tau_{0}$ is the free relaxation time, $V_{\text {th }}$ is the threshold voltage, $V_{1}$ and $V_{2}$ are the low and high gray-level voltages, respectively. Based on the previous studies $[17,26]$, the average gray-to-gray rise and decay time is approximately equal to the sum of free relaxation time $\left(V_{1}=0\right)$ and turn-on time $\left(V_{2}=8\right.$ th gray level). Therefore, in our experiment we set $V_{1}=0$ and $V_{2}=V_{2 \pi}$ and just measured the rise time and decay time between gray levels 1 and 8 for each test cell without the need of measuring all the gray-to-gray transition times.

In experiment, the rise time and decay time of LCM-1107 and LCM-2018 were measured at $T=40,50$ and $60{ }^{\circ} \mathrm{C}$ at $V_{2 \pi}=5 \mathrm{~V}$ and $\lambda=1550 \mathrm{~nm}$. Results are shown in Table 3 for LCM-1107 and Table 4 for LCM-2018. Next, we converted the measured results to the corresponding reflection-type cell, which is four times faster than that of a transmissive cell because its cell gap is one-half of the transmissive one. Furthermore, in each scenario we also need to convert the response time to the corresponding optimal cell gap with $V_{2 \pi}=5 \mathrm{~V}$, as the blue lines depict in Figure 7. Under optimal conditions, the cell gap is thinner and the value of $V_{2 \pi}$ increases to $5 \mathrm{~V}$, which contributes to a faster rise time, as Equation (4) indicates. On the other hand, a thinner cell gap also helps to improve the decay time according to Equations (5) and (6). Therefore, the total response time is reduced significantly by using an optimal cell gap, and the extrapolated results are shown in Table 3 for LCM-1107 and Table 4 for LCM-2018. From Table 3, LCM-1107 has a total response time of $6 \mathrm{~ms}$ at $50{ }^{\circ} \mathrm{C}$. On the other hand, LCM-2018 has an even higher birefringence than LCM-1107. Thus, a thinner cell gap can be used, resulting in a $5.1 \mathrm{~ms}$ total response time at $50{ }^{\circ} \mathrm{C}$ and $4.6 \mathrm{~ms}$ one at $60{ }^{\circ} \mathrm{C}$. That means that by using LCM-2018 we can achieve a $\sim 200 \mathrm{~Hz}$ frame rate for $6 \mathrm{G}$ communication at $\lambda=1550 \mathrm{~nm}$.

Table 3. Measured response time of a transmissive LCM-1107 cell with $d=8.03 \mu \mathrm{m}$ and the extrapolated response time to the corresponding reflective cells at 40,50 and $60^{\circ} \mathrm{C}$ with $\lambda=1550 \mathrm{~nm}$.

\begin{tabular}{cccccccc}
\hline $\boldsymbol{T}\left({ }^{\circ} \mathbf{C}\right)$ & $\boldsymbol{d}(\boldsymbol{\mu \mathrm { m } )}$ & $\boldsymbol{V}_{\text {th }}(\mathbf{V})$ & $\boldsymbol{V}_{\mathbf{2 \pi}}(\mathbf{V})$ & $\boldsymbol{\tau}_{\text {on }}(\mathbf{m s})$ & $\boldsymbol{\tau}_{\text {off }}(\mathbf{m s})$ & $\begin{array}{c}\boldsymbol{\tau}_{\text {total }}(\mathbf{m s}) \\
\text { Transmissive }\end{array}$ & $\begin{array}{c}\boldsymbol{\tau}_{\text {total }} \\
(\mathbf{m s}) \\
\text { Reflective }\end{array}$ \\
\hline 40 & 8.03 & 0.8 & 1.88 & 40.4 & 56.6 & 97.1 & 24.3 \\
40 & 5.88 & 0.8 & 5.0 & 2.4 & 30.4 & 32.8 & 8.2 \\
50 & 8.03 & 0.8 & 1.94 & 27.1 & 39.2 & 66.3 & 16.6 \\
50 & 6.05 & 0.8 & 5.0 & 1.9 & 22.3 & 24.2 & 6.0 \\
60 & 8.03 & 0.8 & 2.04 & 17.9 & 30.9 & 48.8 & 12.2 \\
60 & 6.52 & 0.8 & 5.0 & 1.6 & 20.4 & 22.0 & 5.5 \\
\hline
\end{tabular}

Table 4. Measured response time of a transmissive LCM-2018 cell with $d=8.10 \mu \mathrm{m}$ and the extrapolated response time to the corresponding reflective cells at 40,50 and $60{ }^{\circ} \mathrm{C}$ with $\lambda=1550 \mathrm{~nm}$.

\begin{tabular}{cccccccc}
\hline $\boldsymbol{T}\left({ }^{\circ} \mathbf{C}\right)$ & $\boldsymbol{d}(\boldsymbol{\mu \mathrm { m } )}$ & $\boldsymbol{V}_{\text {th }}(\mathbf{V})$ & $\boldsymbol{V}_{\mathbf{2 \pi}}(\mathbf{V})$ & $\boldsymbol{\tau}_{\text {on }}(\mathbf{m s})$ & $\boldsymbol{\tau}_{\text {off }}(\mathbf{m s})$ & $\begin{array}{c}\boldsymbol{\tau}_{\text {total }}(\mathbf{m s}) \\
\text { Transmissive }\end{array}$ & $\begin{array}{c}\boldsymbol{\tau}_{\text {total }} \\
(\mathbf{m s}) \\
\text { Reflective }\end{array}$ \\
\hline 40 & 8.10 & 0.9 & 1.80 & 54.4 & 52.1 & 106.4 & 26.6 \\
40 & 5.20 & 0.9 & 5.0 & 2.3 & 21.5 & 23.7 & 5.9 \\
50 & 8.10 & 0.9 & 1.84 & 38.3 & 41.5 & 79.8 & 19.9 \\
50 & 5.42 & 0.9 & 5.0 & 1.8 & 18.6 & 20.4 & 5.1 \\
60 & 8.10 & 0.85 & 1.85 & 29.8 & 33.7 & 63.4 & 15.9 \\
60 & 5.73 & 0.85 & 5.0 & 1.7 & 16.8 & 18.5 & 4.6 \\
\hline
\end{tabular}

It should be mentioned here that, in addition to the material parameters and cell gap shown in Equations (4)-(6), the LC response time also depends on the anchoring energy of the alignment layers [27]. Equations (4)-(6) are derived based on strong anchoring energy, such as buffed polyimide alignment layers. If an inorganic $\mathrm{SiO}_{2}$ layer is used, its anchoring energy could be lower. As a result, the corresponding threshold voltage would decrease, and decay time would increase slightly due to the weaker restoring force [28]. 


\section{Coating Design}

Both LCM-1107 and 2018 contain some isothiocyanato (NCS) phenyl-tolane compounds $[29,30]$. Thus, they exhibit a high $\Delta n$, large $\Delta \varepsilon$, and relatively low viscosity. However, due to their long molecular conjugation, the photostability of these high birefringence NCS compounds are usually inadequate, especially in the UV and blue spectral regions. To seal the filling hole of the LCoS panel, we should block the active LC area and use a longer UV wavelength, such as $385 \mathrm{~nm}$, to cure the sealant glue, as discussed in [17].

To protect the high birefringence LC materials from ambient UV and blue light irradiation, we designed a distributed Bragg reflector (DBR) to filter out the wavelength from 300 to $500 \mathrm{~nm}$, while keeping a high transmittance at $1550 \mathrm{~nm}$. Such a DBR film should only cover the active LC area, except for the filling hole, because it is not transparent at $385 \mathrm{~nm}$.

In our design, we applied $\mathrm{TiO}_{2}$ and $\mathrm{SiO}_{2}$ as the high and low refractive index materials, respectively, which are commonly used in DBR fabrication [31-33]. The wavelengthdependent refractive indices of $\mathrm{TiO}_{2}$ and $\mathrm{SiO}_{2}$ were taken from [31] and [32], respectively. Since we require a broad reflection band in the UV-blue region, in our design we adopted two groups of DBR stacks [33] corresponding to the two reflection peaks at 360 and $480 \mathrm{~nm}$, respectively. Each group consists of eight pairs of $\mathrm{TiO}_{2} / \mathrm{SiO}_{2}$. Each pair in the first group (corresponding to the $360 \mathrm{~nm}$ reflection peak) has a thickness of $\mathrm{TiO}_{2}(32 \mathrm{~nm}) / \mathrm{SiO}_{2}(61 \mathrm{~nm})$, and the second group (corresponding to the $480 \mathrm{~nm}$ reflection peak) has the thickness of $\mathrm{TiO}_{2}(47 \mathrm{~nm}) / \mathrm{SiO}_{2}(81 \mathrm{~nm})$. The transmission spectrum of this DBR is shown in Figure 8. The transmittance is less than $0.5 \%$ from 300 to $510 \mathrm{~nm}$ but is as high as $97.2 \%$ at $1550 \mathrm{~nm}$.

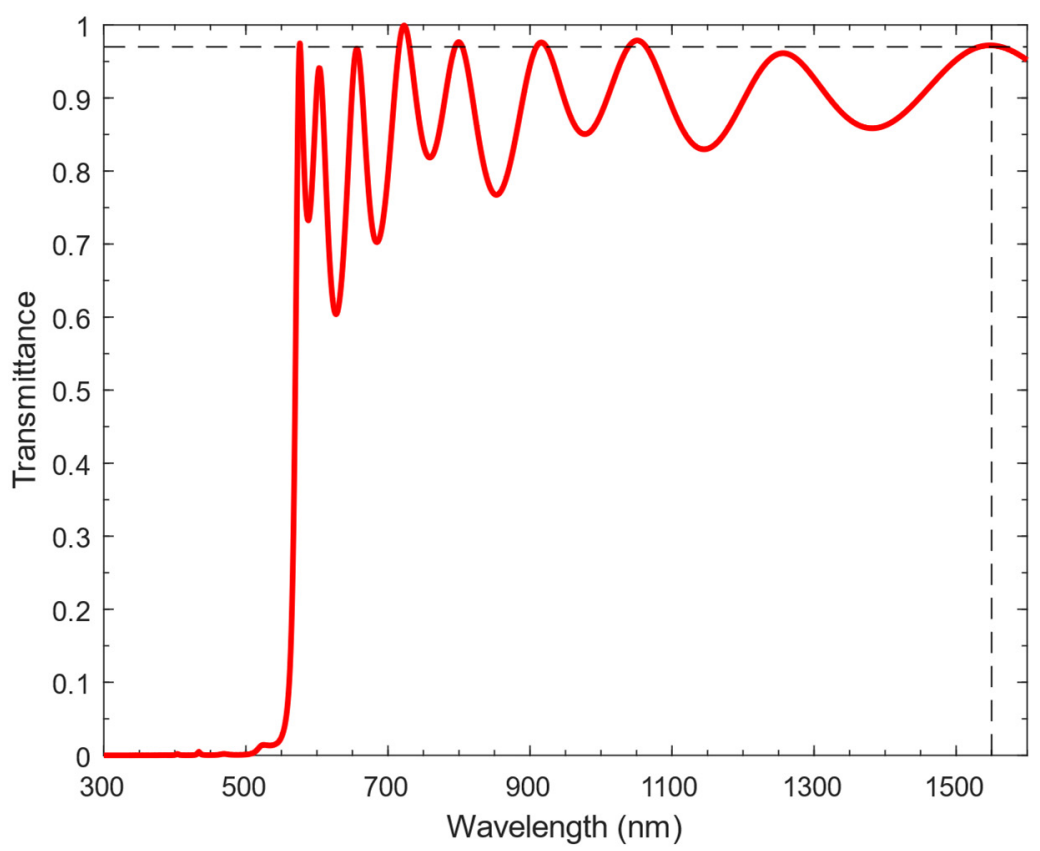

Figure 8. Transmission spectrum of the designed distributed Bragg reflector.

\section{Conclusions}

We reported two high birefringence LC mixtures, LCM-1107 and LCM-2018, for phaseonly LCoS panels intended for 6G communications, whose working wavelength is around $1550 \mathrm{~nm}$. These two materials can easily achieve a total response time of $6 \mathrm{~ms}$ at $50{ }^{\circ} \mathrm{C}$ operating temperature, while keeping the $2 \pi$ phase change voltage at $5 V_{\text {rms }}$. To enhance the photostability, we also designed a DBR coating, which has a transmittance lower than $0.5 \%$ from 300 to $510 \mathrm{~nm}$, and higher than $97 \%$ at $1550 \mathrm{~nm}$. These two materials are promising candidates for LCoS-based 6G communications. 
Author Contributions: Methodology, J.Z. and Z.Y.; writing-original draft preparation, J.Z. and C.M.; writing-review and editing, S.-T.W.; supervision, S.-T.W. All authors have read and agreed to the published version of the manuscript.

Funding: Sony Corporation.

Acknowledgments: The UCF group is indebted to Sony Corp. for the financial support and Sebastian Gauza of LC Matter for providing the liquid crystal materials.

Conflicts of Interest: The authors declare no conflict of interest.

\section{References}

1. Brackett, C.A. Dense wavelength division multiplexing networks: Principles and applications. IEEE J. Sel. Areas Commun. 1990, 8 , 948-964. [CrossRef]

2. Zhu, L.; Zhu, G.; Wang, A.; Wang, L.; Ai, J.; Chen, S.; Du, C.; Liu, J.; Yu, S.; Wang, J. 18 km low-crosstalk OAM+ WDM transmission with 224 individual channels enabled by a ring-core fiber with large high-order mode group separation. Opt. Lett. 2018, 43, 1890-1893. [CrossRef] [PubMed]

3. Panwar, N.; Sharma, S.; Singh, A.K. A survey on 5G: The next generation of mobile communication. Phys. Commun. 2016, 18, 64-84. [CrossRef]

4. Giordani, M.; Polese, M.; Mezzavilla, M.; Rangan, S.; Zorzi, M. Toward 6G networks: Use cases and technologies. IEEE Commun. Mag. 2020, 58, 55-61. [CrossRef]

5. Chowdhury, M.Z.; Shahjalal, M.; Ahmed, S.; Jang, Y.M. 6G wireless communication systems: Applications, requirements, technologies, challenges, and research directions. IEEE Open J. Commun. Soc. 2020, 1, 957-975. [CrossRef]

6. Tibuleac, S.; Filer, M. Transmission impairments in DWDM networks with reconfigurable optical add-drop multiplexers. J. Lightwave Technol. 2010, 28, 557-568. [CrossRef]

7. Wang, S.; Feng, X.; Gao, S.; Shi, Y.; Dai, T.; Yu, H.; Tsang, H.K.; Dai, D. On-chip reconfigurable optical add-drop multiplexer for hybrid wavelength/mode-division-multiplexing systems. Opt. Lett. 2017, 42, 2802-2805. [CrossRef]

8. Geng, M.; Jia, L.; Zhang, L.; Yang, L.; Chen, P.; Wang, T.; Liu, Y. Four-channel reconfigurable optical add-drop multiplexer based on photonic wire waveguide. Opt. Express 2009, 17, 5502-5516. [CrossRef]

9. Ma, Y.; Stewart, L.; Armstrong, J.; Clarke, I.; Baxter, G.W. Recent Progress of Wavelength Selective Switch. J. Lightwave Technol. 2020, 39, 896-903. [CrossRef]

10. Marom, D.M.; Neilson, D.T.; Greywall, D.S.; Pai, C.S.; Basavanhally, N.R.; Aksyuk, V.A.; López, D.O.; Pardo, F.; Simon, M.E.; Low, Y.; et al. Wavelength-selective 1 x K switches using free-space optics and MEMS micromirrors: Theory, design, and implementation. J. Lightwave Technol. 2005, 23, 1620-1630. [CrossRef]

11. Scherger, B.; Reuter, M.; Scheller, M.; Altmann, K.; Vieweg, N.; Dabrowski, R.; Deibel, J.A.; Koch, M. Discrete terahertz beam steering with an electrically controlled liquid crystal device. J. InfraredMillim. Terahertz Waves 2012, 33, 1117-1122. [CrossRef]

12. Baxter, G.; Frisken, S.; Abakoumov, D.; Zhou, H.; Clarke, I.; Bartos, A.; Poole, S. Highly programmable wavelength selective switch based on liquid crystal on silicon switching elements. In Proceedings of the 2006 Optical Fiber Communication Conference and the National Fiber Optic Engineers Conference, Anaheim, CA, USA, 5-10 March 2006.

13. Wang, M.; Zong, L.; Mao, L.; Marquez, A.; Ye, Y.; Zhao, H.; Vaquero, C.F.J. LCoS SLM study and its application in wavelength selective switch. Photonics 2017, 4, 22. [CrossRef]

14. Frisken, S.; Baxter, G.; Abakoumov, D.; Zhou, H.; Clarke, I.; Poole, S. Flexible and grid-less wavelength selective switch using LCOS technology. In Proceedings of the 2011 Optical Fiber Communication Conference and Exposition and the National Fiber Optic Engineers Conference, Los Angeles, CA, USA, 6-10 March 2011.

15. Zou, J.; Yang, Q.; Hsiang, E.L.; Ooishi, H.; Yang, Z.; Yoshidaya, K.; Wu, S.T. Fast-response liquid crystal for spatial light modulator and LiDAR applications. Crystals 2021, 11,93. [CrossRef]

16. Lazarev, G.; Chen, P.J.; Strauss, J.; Fontaine, N.; Forbes, A. Beyond the display: Phase-only liquid crystal on Silicon devices and their applications in photonics. Opt. Express 2019, 27, 16206-16249. [CrossRef]

17. Huang, Y.; He, Z.; Wu, S.T. Fast-response liquid crystal phase modulators for augmented reality displays. Opt. Express 2017, 25, 32757-32766. [CrossRef]

18. Yang, Q.; Zou, J.; Li, Y.; Wu, S.T. Fast-response liquid crystal phase modulators with an excellent photostability. Crystals 2020, 10, 765. [CrossRef]

19. He, Z.; Yin, K.; Wu, S.T. Miniature planar telescopes for efficient, wide-angle, high-precision beam steering. Light Sci. Appl. 2021, 10, 134. [CrossRef] [PubMed]

20. Wu, S.T.; Wu, C.S. Rotational viscosity of nematic liquid crystals a critical examination of existing models. Liq. Cryst. 1990, 8 , 171-182. [CrossRef]

21. Dąbrowski, R.; Kula, P.; Herman, J. High Birefringence Liquid Crystals. Crystals 2013, 3, 443-482. [CrossRef]

22. Wu, S.T.; Efron, U.; Hess, L.D. Birefringence measurements of liquid crystals. Appl. Opt. 1984, 23, 3911-3915. [CrossRef] [PubMed]

23. Wu, S.T. Birefringence dispersions of liquid crystals. Phys. Rev. A 1986, 33, 1270-1274. [CrossRef] 
24. Wu, S.T.; Lackner, A.M.; Efron, U. Optimal operation temperature of liquid crystal modulators. Appl. Opt. 1987, $26,3441-3445$. [CrossRef]

25. Wu, S.T. Design of a liquid-crystal-based electro-optic filter. Appl. Opt. 1989, 28, 48-52. [CrossRef]

26. Chen, H.; Gou, F.; Wu, S.T. Submillisecond-response nematic liquid crystals for augmented reality displays. Opt. Mater. Express 2017, 7, 195-201. [CrossRef]

27. Nie, X.; Xianyu, H.; Lu, R.; Wu, T.X.; Wu, S.-T. Anchoring energy and cell gap effects on liquid crystal response time. J. Appl. Phys. 2007, 101, 103110. [CrossRef]

28. Jiao, M.; Ge, Z.; Song, Q.; Wu, S.T. Alignment layer effects on thin liquid crystal cells. Appl. Phys. Lett. 2008, 92, 061102. [CrossRef]

29. Gauza, S.; Li, L.; Wu, S.T.; Spadlo, A.; Dabrowski, R.; Tzeng, Y.N.; Cheng, K.L. High birefringence and high resistivity isothiocyanate-based nematic liquid crystal mixtures. Liq. Cryst. 2005, 32, 1077-1085. [CrossRef]

30. Gauza, S.; Wang, H.; Wen, C.H.; Wu, S.T.; Seed, A.; Dabrowski, R. High birefringence isothiocyanato tolane liquid crystals. Jpn. J. Appl. Phys. 2003, 42, 3463-3466. [CrossRef]

31. Lin, K.C.; Lee, W.K.; Wang, B.K.; Lin, Y.H.; Chen, H.H.; Song, Y.H.; Huang, Y.H.; Shih, L.W.; Wu, C.C. Modified distributed Bragg reflector for protecting organic light-emitting diode displays against ultraviolet light. Op. Express 2021, 29, 7654-7665. [CrossRef] [PubMed]

32. Gao, L.; Lemarchand, F.; Lequime, M. Refractive index determination of $\mathrm{SiO}_{2}$ layer in the UV/Vis/NIR range: Spectrophotometric reverse engineering on single and bi-layer designs. J. Eur. Opt. Soc. Rapid Publ. 2013, 8, 13010. [CrossRef]

33. Ding, X.; Gui, C.; Hu, H.; Liu, M.; Liu, X.; Lv, J.; Zhou, S. Reflectance bandwidth and efficiency improvement of light-emitting diodes with double-distributed Bragg reflector. Appl. Opt. 2017, 56, 4375-4380. [CrossRef] [PubMed] 